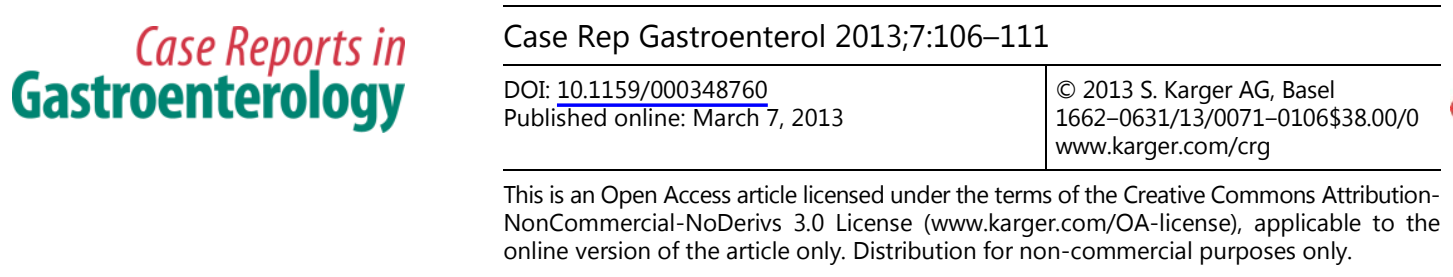

\title{
Metastatic Breast Carcinoma Presenting as a Sigmoid Stricture: Report of a Case and Review of the Literature
}

\author{
A. Nikkar-Esfahani Bhaskar G. Kumar Douglas Aitken \\ Robert G. Wilson \\ Department of Colorectal Surgery, James Cook University, Hospital, Middlesbrough, UK
}

\section{Key Words}

Breast cancer · Lobular carcinoma · Colonic metastases $\cdot$ Rectal metastases

\begin{abstract}
Metastatic spread of breast carcinoma to the colon and rectum is rare. We report the case of a patient treated for lobular breast carcinoma presenting 17 years later with metastatic breast cancer of the colon. A 63-year-old lady with a past history of right-sided invasive lobular carcinoma of the breast presented with persistent diarrhoea. Colonoscopy with biopsies revealed a benign-looking stricture at the rectosigmoid junction. A CT scan of the abdomen and pelvis revealed a benign-looking stricture in keeping with a probable diverticular stricture. A Hartmann procedure was performed and histology revealed a metastatic lobular carcinoma with oestrogen and progesterone receptor-positive status. Treatment was commenced with letrozole and the patient remains well under clinical surveillance. In a patient with a history of breast carcinoma who presents with gastrointestinal symptoms the possibility of gastrointestinal tract spread should always be considered. Endoscopic diagnosis may be misleading with pathological diagnosis only being made following surgical resection. A history of breast carcinoma must be declared to the histopathologist following surgical resection so that an accurate diagnosis is made and appropriate treatment is commenced.
\end{abstract}




\section{Introduction}

Carcinoma of the breast remains the commonest malignancy in women accounting for over 11,000 deaths in the UK each year [1]. With early diagnosis and treatment, many women may become long-term breast cancer survivors; however, recurrence and metastasis are quite common. The commonest metastatic sites for breast cancer are bone, lung, and liver. Gastrointestinal tract (GIT) metastasis and carcinomatosis from primary breast cancer are rare [2].

In 1993 in a landmark study, Borst and Ingold [3] compared the metastatic patterns of invasive lobular carcinoma (LC) and invasive ductal carcinoma (DC). The series monitored the pattern of metastatic disease in 2,604 breast cancer sufferers over an 18-year period. When compared with other breast cancer subtypes, infiltrating LC was found to metastasize more frequently to the GIT, gynaecological organs, peritoneum, retroperitoneum, adrenal glands or bone marrow. Only 17 patients $(<1 \%)$ out of this large cohort were found to have metastasis to the GIT.

In 1968 Asch et al. [4] published the largest case series of breast cancer metastasis in the medical literature that reports GIT metastasis secondary to breast cancer. This autopsy series reported 52 cases of GIT metastasis secondary to breast cancer. The distribution of these metastases was as follows: oesophagus (25\%), stomach (25\%), small intestine (28\%) and least frequently colon (19\%) and rectum (4\%). There was no mention of the primary histological subtype in this series.

We report the case of a patient treated for lobular breast carcinoma presenting 17 years later with metastatic breast cancer of the colon.

\section{Case Report}

A 63-year-old lady presented with a 3-week history of persistent diarrhoea. She denied any evidence of blood or mucus in her stool. There was no history of vomiting but examination revealed mild abdominal distension. There was no history of previous abdominal surgery. She had undergone a right-sided mastectomy for invasive LC 17 years before. She had been treated with tamoxifen for 5 years subsequent to her mastectomy. On examination her abdomen was mildly distended but was soft and non-tender. Rectal examination revealed a sentinel pile at the 11 o'clock position but no other abnormality. Plain abdominal and chest X-rays were unremarkable.

CT of abdomen and pelvis revealed mucosal thickening involving the whole rectum but no other abnormality. A colonoscopy was subsequently arranged which revealed a stricture of the sigmoid colon that was impassable. Biopsies revealed no evidence of dysplasia or malignancy. Repeat colonoscopies and biopsies were also inconclusive.

After discussion at the multidisciplinary team meeting she was listed for a Hartmann procedure. Histology from the resected specimen revealed a metastatic LC to the distal bowel wall (fig. 1, fig. 2). There was no evidence of lymph node involvement. Immunohistochemistry revealed the metastasis to be of oestrogen receptor-positive and progesterone receptor-positive status. She was subsequently started on letrozole hormone therapy and is doing well 1 year after her Hartmann procedure. 
Nikkar-Esfahani et al.: Metastatic Breast Carcinoma Presenting as a Sigmoid Stricture: Report of a Case and Review of the Literature

\section{Discussion}

Autopsy studies have reported metastatic breast cancer of the GIT but the true incidence is probably underestimated. Furthermore as the number of breast cancer survivors continues to increase, metastatic presentations are also likely to increase [4]. The GIT is a rare site of metastatic disease but breast cancer is the commonest primary tumour to metastasise to the GIT. Metastatic disease to the extrahepatic GIT from breast carcinoma usually originates from lobular or mixed DC [2].

A review of the literature has shown a limited number of cases of breast cancer with metastatic spread to the colon and the rectum (table 1). Overall 19 cases have been described in the literature with the rectum and sigmoid accounting for only 6 previous reported cases.

LC accounts for only $8-14 \%$ of all breast adenocarcinomas [3]. It is the commonest histological type of breast cancer following DC. There is growing evidence to support the association between the use of hormone replacement therapy and a higher risk of invasive LC. LC has a distinct biology and a greater tendency to be multifocal and bilateral than DC [4]. The metastatic pattern of LC and DC differ. LC has a tendency to metastasise to unusual locations, with metastases to the GIT, gynaecological organs and peritoneum/retroperitoneum being more characteristic of LC. In contrast, DC tends to metastasise to the liver, lung and brain [5]. In a large retrospective analysis of patterns of metastatic spread of LC it was shown that within the GIT the small bowel appears to be the commonest site followed by the stomach [3]. Metastases to the colon and rectum are particularly rare.

The clinical presentation of breast cancer metastasising to the GIT is varied and nonspecific. This makes establishing a diagnosis difficult and often comes as an unexpected finding several years from the original diagnosis of the breast lesion. In the cases reported in the literature, the median interval from diagnosis of breast cancer to presentation of GIT metastases ranged from simultaneous presentation to 26 years after the initial diagnosis $[6,7]$.

Endoscopic investigation is essential to determine the site of the lesion and to assess the appearance of the tumour which may be distinct from a primary lesion [8]. Endoscopic biopsy may prove to be normal particularly when biopsies are too superficial. From our literature review it would appear that the majority of these tumours present as diffuse thickening of the colonic wall resembling linitis plastica. Other descriptions include ulcerated or nodular lesions mimicking Crohn's disease [9]. Histological diagnosis can be difficult for the pathologist who has not been informed of the patient's background of breast cancer. The pathological appearance of these tumours has been described as a typical arrangement known as 'Indian files' - a pattern of infiltration that provokes an intense fibrous reaction leading to the linitis plastica appearance. A lack of dysplasia of the colonic/rectal glandular epithelium may help to distinguish a primary from a secondary lesion [10].

The management of these patients is controversial, reflecting the generally low level of clinical experience in dealing with such patients. Based on our literature review, following the initial surgical treatment, patients received a varied combination of chemotherapy, hormone therapy and radiotherapy.

Survival in patients with GIT metastases from breast cancer is generally poor due to late presentation and advanced disease. Palliative surgery is indicated in those with advanced symptoms such as bowel obstruction from locally advanced disease. In a retrospective analysis of breast cancer patients with gastrointestinal metastases surgical intervention did not significantly extend overall survival [11]. In the same series the median overall survival after diagnosis was 28 months. This poor survival may reflect a more widespread metastatic 
Nikkar-Esfahani et al.: Metastatic Breast Carcinoma Presenting as a Sigmoid Stricture: Report of a Case and Review of the Literature

disease in these patients. Moreover the difference in metastatic spread of lobular breast cancer raises the question as to whether these patients should have a different protocol for follow-up particularly in the presence of gastrointestinal symptoms.

Although GIT metastases from breast cancer are a rare entity in patients with lobular breast carcinoma presenting with gastrointestinal symptoms, the possibility of disease recurrence must always be kept in mind. Furthermore it should also be remembered that this pattern of metastatic spread is not limited to LC but may also be seen with the commoner ductal breast adenocarcinoma. Endoscopic diagnosis may be misleading with pathological diagnosis only being made following surgical resection. With the rising survival of breast cancer patients future clinicians may see an increasing incidence of this unusual pattern of metastatic spread of breast cancer.

\section{Acknowledgements}

We would like to thank Dr. Adrienne Mutton for her input on histological slides.

\section{References}

1 Cancer Research UK: Breast cancer statistics. http://www.cancerresearchuk.org/cancer-info/cancerstats/ types/breast/, last viewed on 01/07/2012.

- Nazareno J, Taves D, Preiksaitis HG: Metastatic breast cancer to the gastrointestinal tract: a case series and review of the literature. World J Gastroenterol 2006;12:6219-6224.

-3 Borst MJ, Ingold JA: Metastatic patterns of invasive lobular versus invasive ductal carcinoma of the breast. Surgery 1993;114:637-641; discussion 641-642.

-4 Asch MJ, Wiedel PD, Habif DV: Gastrointestinal metastases from carcinoma of the breast. Arch Surg 1968;96: 840-843.

5 Fondrinier E, Guérin 0, Lorimier G: A comparative study of metastatic patterns of ductal and lobular carcinoma of the breast from two matched series (376 patients) (in French). Bull Cancer 1997;84: 1101-1107.

6 Haberstich R, Tuech J, Wilt M, Rodier JF: Anal localization as first manifestation of metastatic ductal breast carcinoma. Tech Coloproctol 2005;9:237-238.

7 Theraux J, Bretagnol F, Guedj N, Cazals-Hatem D, Panis Y: Colorectal breast carcinoma metastasis diagnosed as an obstructive colonic primary tumor. A case report and review of the literature. Gastroenterol Clin Biol 2009;33:1114-1117.

8 Bamias A, Baltayiannis G, Kamina S, Fatouros M, Lymperopoulos E, Agnanti N, Tsianos E, Pavlidis N: Rectal metastases from lobular carcinoma of the breast: report of a case and literature review. Ann Oncol 2001;12: 715-718.

-9 Koos L, Field RE: Metastatic carcinoma of breast simulating Crohn's disease. Int Surg 1980;65:359-362.

10 Franceschini G, Manno A, Mulè A, Verbo A, Rizzo G, Sermoneta D, Petito L, D’alba P, Maggiore C, Terribile D, Masetti R, Coco C: Gastro-intestinal symptoms as clinical manifestation of peritoneal and retroperitoneal spread of an invasive lobular breast cancer: report of a case and review of the literature. BMC Cancer 2006;6:193.

11 McLemore EC, Pockaj BA, Reynolds C, Gray RJ, Hernandez JL, Grant CS, Donohue JH: Breast cancer: presentation and intervention in women with gastrointestinal metastasis and carcinomatosis. Ann Surg Oncol 2005;12:886-894.

12 Cervi G, Vettoretto N, Vinco A, Cervi E, Villanacci V, Grigolato P, Giulini SM: Rectal localization of metastatic lobular breast cancer: report of a case. Dis Colon Rectum 2001;44:453-455.

13 Uygun K, Kocak Z, Altaner S, Cicin I, Tokatli F, Uzal C: Colonic metastasis from carcinoma of the breast that mimics a primary intestinal cancer. Yonsei Med J 2006;47:578-582.

14 Daniels RI, Layer GT, Chisholm EM: Bowel obstruction due to extrinsic compression by metastatic lobular carcinoma of the breast. J R Soc Promot Health 2002;122:61-62.

15 Schwarz RE, Klimstra DS, Turnbull AD: Metastatic breast cancer masquerading as gastrointestinal primary. Am J Gastroenterol 1998;93:111-114.

16 Feng CL, Chou JW, Huang SF: Colonic metastasis from carcinoma of the breast presenting with colonic erosion. Endoscopy 2009;41(suppl 2):E276-E277. 


\section{Case Reports in \\ Gastroenterology}

\begin{tabular}{l|l}
\hline \multicolumn{2}{l}{ Case Rep Gastroenterol 2013;7:106-111 } \\
\hline DOI: $\underline{10.1159 / 000348760}$ & $\begin{array}{l}\text { ○ 2013 S. Karger AG, Basel } \\
\text { www.karger.com/crg }\end{array}$ \\
\hline
\end{tabular}

Nikkar-Esfahani et al.: Metastatic Breast Carcinoma Presenting as a Sigmoid Stricture:

Report of a Case and Review of the Literature

17 Alves de Lima DC, Alberti LR: Breast cancer metastasis to the colon. Endoscopy 2011;43(suppl 2 UCTN): E143-E144.

18 Koutsomanis D, Renier JF, Ollivier R, Moran A, el-Haite AA: Colonic metastasis of breast carcinoma. Hepatogastroenterology 2000;47:681-682.

19 Rabau MY, Alon RJ, Werbin N, Yossipov Y: Colonic metastases from lobular carcinoma of the breast. Report of a case. Dis Colon Rectum 1988;31:401-402.

20 Okido M, Seo M, Hamada Y, et al: Metastatic breast carcinoma simulating linitis plastica of the colon: report of a case. Surg Today 2011;41:542-545.

-21 Vaidya JS, Mukhtar H, Bryan R: Colonic metastasis from a breast cancer - a case report and a few questions. Eur J Surg Oncol 2002;28:463-464.

22 Yokota T, Kunii Y, Kagami M, et al: Metastatic breast carcinoma masquerading as primary colon cancer. Am J Gastroenterol 2000;95:3014-3016.

23 Dhar S, Kulaylat MN, Gordon K, Lall P, Doerr RJ: Solitary papillary breast carcinoma metastasis to the large bowel presenting as primary colon carcinoma: case report and review of the literature. Am Surg 2003;69: 799-803.

-24 Shimonov M, Rubin M: Metastatic breast tumors imitating primary colonic malignancies. Isr Med Assoc J 2000;2:863-864.

-25 Signorelli C, Pomponi-Formiconi D, Nelli F, Pollera CF: Single colon metastasis from breast cancer: a clinical case report. Tumori 2005;91:424-427.

-26 Efthimiadis C, Kosmidis C, Fotiadis P, Anthimidis G, Vasiliadou K, Mekras A, Ioannidou G, Basdanis G: Breast cancer metastatic to the rectum: a case report. Tech Coloproctol 2011;15(suppl 1):S91-S93.

27 Murukutla S, Vivekanandaraja A, Paramanathan K, Kong F, Varma S: Isolated colonic metastasis from primary invasive ductal breast carcinoma: role of tumor marker in early diagnosis. J Med Cases 2012;3: 49-53.

Table 1. Summary of cases reported of metastatic spread of breast carcinoma to the colon and rectum revealing the original type of histology, age at presentation, time since diagnosis as well as site and morphology of metastasis

\begin{tabular}{lllllll}
\hline $\begin{array}{l}\text { Reference } \\
\text { (first author) }\end{array}$ & Age & Original histology & $\begin{array}{l}\text { Time since } \\
\text { diagnosis, } \\
\text { years }\end{array}$ & Presentation & $\begin{array}{l}\text { Site of } \\
\text { metastasis }\end{array}$ & Morphology \\
\hline Uygun [13] & 46 & ductal/lobular & 3.5 & change of bowel habit & bowel obstruction & caecum \\
Daniels [14] & 87 & lobular & 9 & abdominal mass, PR bleeding & transverse & N/A \\
Schwarz [15] & 78 & ductal/lobular & 0.4 & ascending & N/A \\
Theraux [7] & 69 & ductal & 28 & Bowel obstruction & transverse & N/A \\
Cervi [12] & 59 & lobular & 8 & bowel obstruction, PR bleeding & rectum & N/A \\
Dhar [23] & 75 & intraductal papillary & 6 & abdominal pain, PR bleeding & sigmoid & N/A \\
Shimonov [24] & 65 & ductal & 2 & change of bowel habit & sigmoid & N/A \\
Shimonov [24] & 73 & ductal & 6 & change of bowel habit & sigmoid & N/A \\
Shimonov [24] & 72 & lobular & 12 & abdominal distension & rectum & N/A \\
Vaidya [21] & 56 & ductal & 5 & change of bowel habit, weight loss & descending & polypoid tumour \\
Signorelli [25] & 62 & lobular & 12 & abdominal pain, change of bowel habit & caecum & N/A \\
Efthimiadis [26] & 74 & lobular & 5 & abdominal pain, change of bowel habit & rectum & N/A \\
Murukutla [27] & 59 & ductal & 1 & abdominal pain & ascending & N/A \\
Feng [16] & 49 & ductal & 2 & abdominal pain & transverse & colonic erosion \\
Alves de Lima [17] & 74 & lobular & 7 & anaemia & ascending & stricture \\
Koutsomanis [18] & 65 & ductal & 4 & anaemia & ascending & N/A \\
Rabau [19] & 53 & lobular & 7 & obstruction & caecum & stricture \\
Okido [20] & 48 & mixed & 5 & abdominal pain & N/A & stricture \\
Yokota [22] & 57 & ductal & 10 & asymptomatic & stricture \\
\hline & & & & &
\end{tabular}




\begin{tabular}{rl|l} 
Case Reports in & \multicolumn{2}{l}{} \\
\cline { 2 - 3 } Gastroenterology & Case Rep Gastroenterol 2013;7:106-111 & $\begin{array}{l}\text { ○ 2013 S. Karger AG, Basel } \\
\text { www.karger.com/crg }\end{array}$ \\
\cline { 2 - 3 } & DOI: $\underline{10.1159 / 000348760}$ & Presenting as a Sigmoid Stricture:
\end{tabular}

Nikkar-Esfahani et al.: Metastatic Breast Carcinoma Presenting as a Sigmoid Stricture:

Report of a Case and Review of the Literature

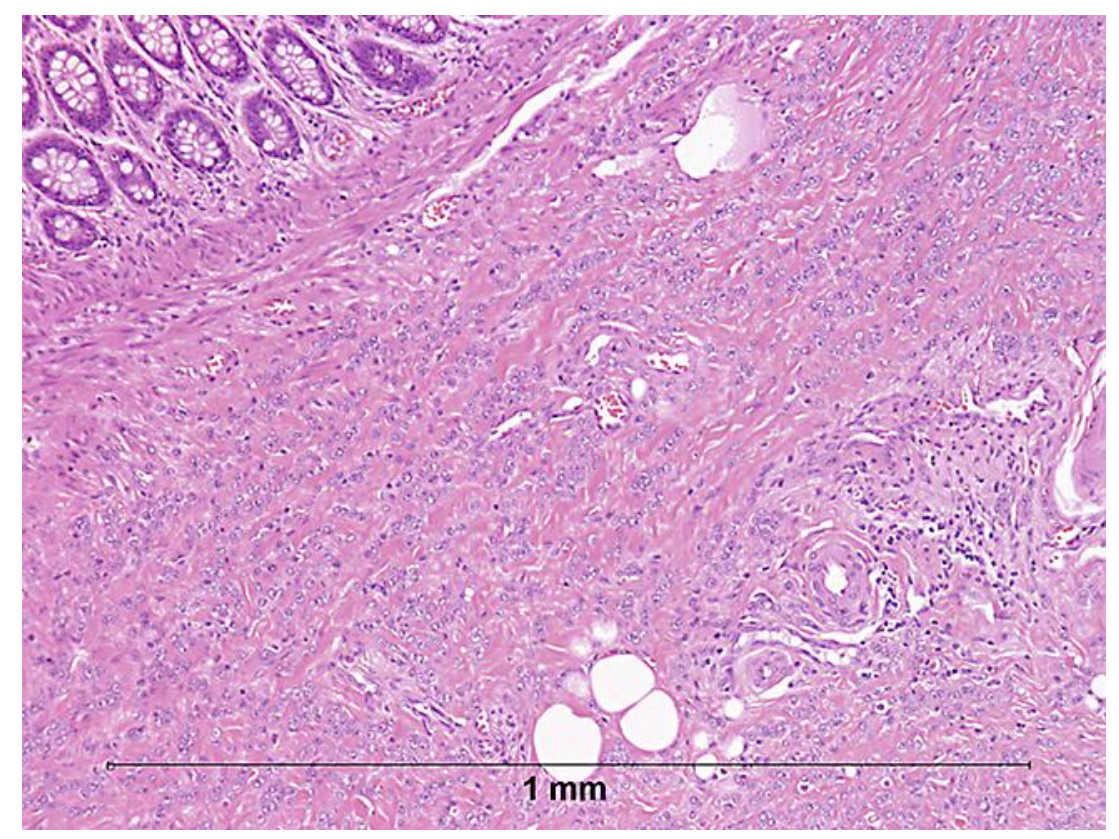

Fig. 1. High power view of colonic mucosa and submucosa showing an atypical infiltrate of small cells with high nuclear to cytoplasmic ratios within the submucosa. The latter demonstrate the typical 'Indian file' cord-like invasive pattern of metastatic LC.

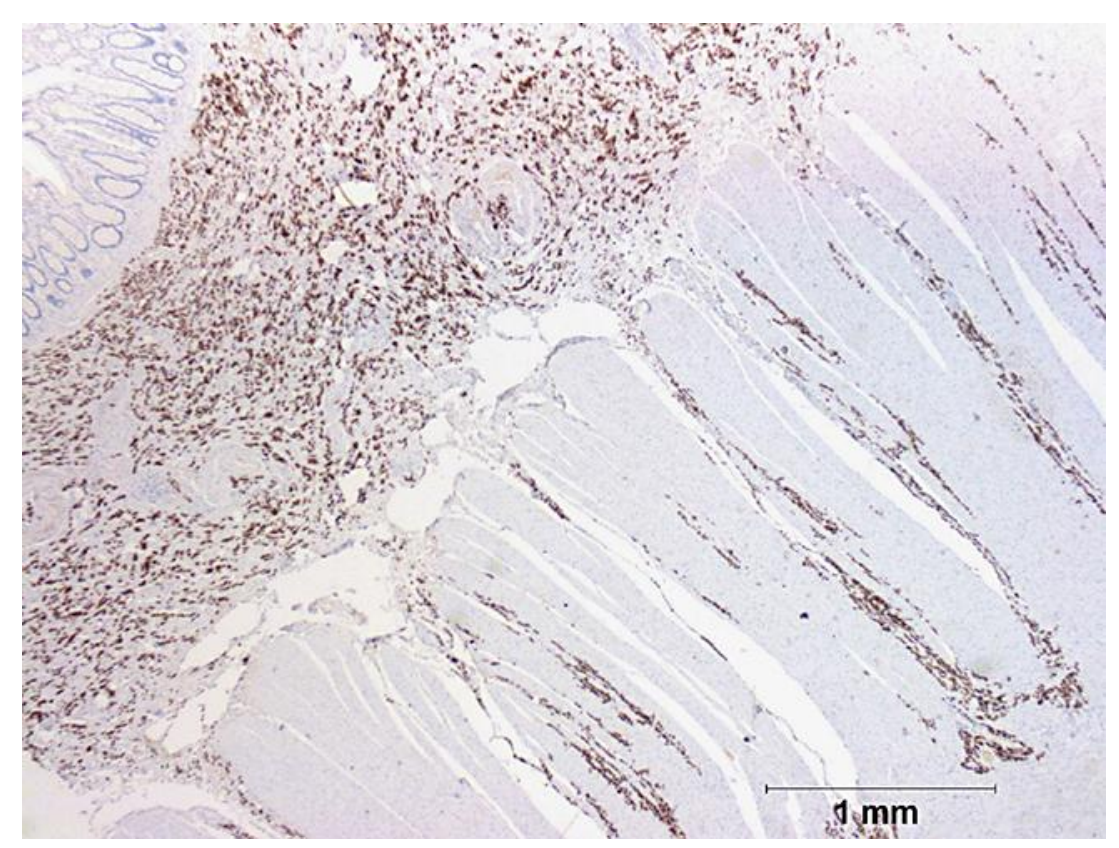

Fig. 2. Low-power microscopic view of the colon in which both the submucosa and muscularis propria are extensively infiltrated by metastatic LC cells highlighted by positive immunohistochemical nuclear staining for oestrogen receptor. 